\title{
EDUCACIÓN PARA EL DESARROLLO EDUCAR EN Y PARA LA COOPERACIÓN Y LA SOLIDARIDAD
}

\author{
Juan José Celorio Díaz \\ Universidad del País Vasco
}

\begin{abstract}
RESUMEN. El autor indaga sobre el impacto de las nuevas tendencias de la Globalización y el Neoliberalismo en los Sistemas Educativos con el objetivo de apuntar las dificultades y potencialidades de una Educación para la Solidaridad y la Cooperación. Desde una perspectiva de Educación para el Desarrollo rastrea las bases materiales, organizativas y culturales, para la construcción de un Movimiento Educativo desde la Solidaridad y Cooperación. Observa su situación en la Reforma Educativa, la tradición de los Movimientos de Renovación Pedagógica y el pensamiento de Freinet y en el mundo de las ONGDs y Sindicatos de Enseñanza. Apuesta por una comunicación y cooperación entre estos ámbitos.
\end{abstract}

ABSTRACT. The author finds aut the new tendencies of Globalitation and Neoliberalism in the Educative Sistems with the aim of pointing out the difficulties and potentialities of an Education for Solidarity and Cooperation. From a perspective of an Education for the Development, he trails the material, organizative and cultural bases for the construction of an Educative Movement for the Solidarity and Cooperation. He points out its situation in the Educational Reform. He observes the tradition of the Movement of a Pedagogical Renovation and Freinet's thoughts in the ONGDs (no goverment organitations) world and Teaching Trades Union. Celorio bets on both comunication and Coopertion fields.

"Si los nuevos medios han modificado profundamente la cultura en la que surgieron y si ésta ha modificado a su vez profundamente la manera de ver, de sentir y de pensar la realidad por parte de las nuevas generaciones, es imprescindible que la educación y la cultura sepan modificar también profundamente sus propias estructuras, esquemas y criterios para adecuarse a unos sujetos modelados por la sociedad en la que nacieron"

(Joan Ferrés (2000) Educar en una cultura del espectáculo)

\section{El FMI celebra su cumbre en Washington gracias a una implacable represión policial}

La policía impidió ayer que unos 10.000 manifestantes, en su mayoría jóvenes de izquierdas y ecologistas, bloquearan la asamblea del Fondo Monetario Internacional (FMI) en Washington. Ajenos a los disturbios, los líderes de las finanzas subrayaron las buenas perspectivas de la economía mundial y debatieron posibles reformas para atajar nuevas crisis.

(El País Digital. 17-Abril-2000. http://www.elpais.es) 
"No hay que sorprenderse si, en el plano escolar, los niños no se interesan por los textos aprendidos de memoria, por los ejercicios, las explicaciones, los modos disciplinarios y de vida que datan de "su" prehistoria. Cuando salen de una clase que ha sido llevada al estilo 1900, se subirán a su moto, conducirán quizá automóviles y tractores; discutirán problemas que antes eran desconocidos para ustedes. Y sobre todo, los medios de información los hacen vivir en un mundo que no tiene nada en común con la vieja escuela donde ustedes se obstinan en mantenerlos.

Dirán ustedes entonces: los niños de hoy no se interesan ya por la escuela, creen saberlo todo y no saben ni siquiera leer correctamente. No hablemos de la ortografía que es desastrosa, ni de las adquisiciones escolares siempre insuficientes. He aquí un problema escolar.

Y tienen razón: los niños de hoy no reaccionan como los niños de hace 20 años ni de hace 10 años. El trabajo escolar no les interesa porque no se inscribe ya en su mundo"

(C.Freinet. Técnicas Freinet de la Escuela Moderna. 1964)

Entre el primero de los textos que encabeza este artículo y el tercero median casi cuarenta años y sin embargo, una misma corriente de fondo parece unirles pese al tiempo transcurrido. Sin embargo en medio han ocurrido demasiadas cosas, tantas como para que los y las jóvenes -y otros no tan jóvenes- se movilicen a favor de la inmensa pobreza y exclusión de las mayorías mundiales frente a las políticas globalizadoras de las instituciones financieras internacionales. Su movilización y organización se ha hecho posible a través de una de las nuevas tecnologías que son vedettes en los nuevos valores de Bolsa, Internet, la Red de Redes. ¿Qué está ocurriendo? ¿Qué implicaciones y retos plantea a las instituciones y actores educativos?

En estas páginas se abordan algunas reflexiones sobre estas cuestiones intentando ofrecer algunas líneas de referencia para el debate y la acción en el seno de la comunidad educativa, especialmente de los y las docentes que día a día abren sus aulas, pero también para la comunidad académica crítica. También debe explicitarse al comenzar estas líneas que no lo hacemos desde posiciones "neutralistas" sino desde el entendimiento que toda acción educativa, más allá de su vertiente pedagógica es una acción ética, política, ciudadana en definitiva que afecta, se quiera o no, se sea consciente o no, a la "res-pública". Por tanto, este artículo pretende contribuir al debate sobre las posibilidades y enfoques sobre las que es posible edificar una educación para la solidaridad y la cooperación en el interior de los sistemas educativos formales y en la época de la globalización al comienzo del nuevo milenio.

Se reflexiona en primer lugar sobre algunas tendencias transformadoras que definen las llamadas "sociedades de riesgo" y su impacto en los sistemas educativos. A continuación, se pretenden discutir los posibles obstáculos y posibilidades de una educación para el desarrollo, con el propósito de buscar posibles líneas estratégicas.

\section{El impacto educativo de la Glocalización de Riesgo}

\subsection{La Glocalización como Reordenación Social y Cultural}

A lo largo de la última década ha venido apareciendo una literatura que coloca como centro del análisis, en la aproximación a la situación de los sistemas sociales posteriores a la crisis del bloque soviético, a la llamada cuestión de la Globalización, sus características, tendencias, impactos, resistencias, etc... 


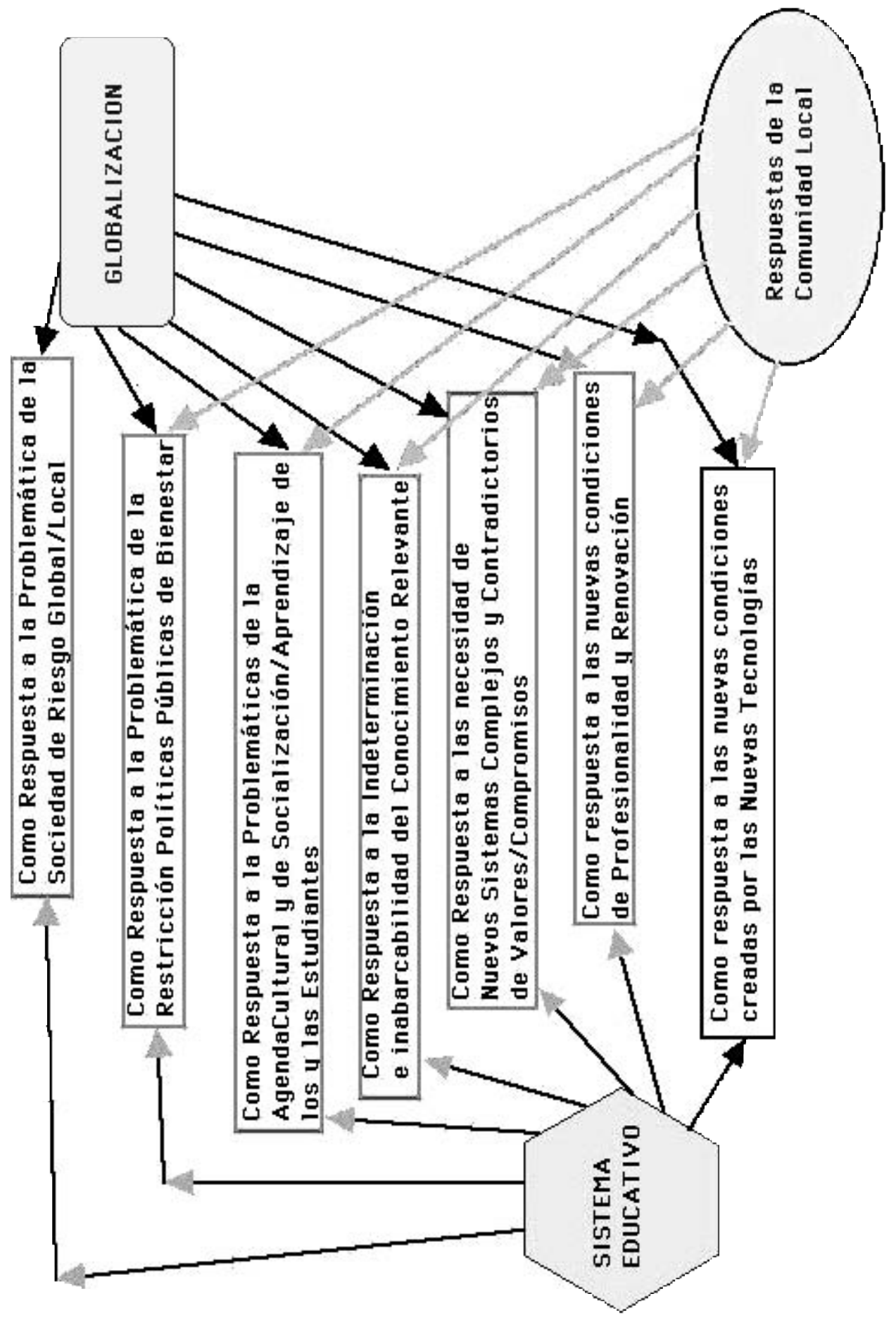


DOS TRADICIONES DE COOPERACION EDUCATIVA

EDUCACION EMANCIPADORA PARA LA MODERNIDAD
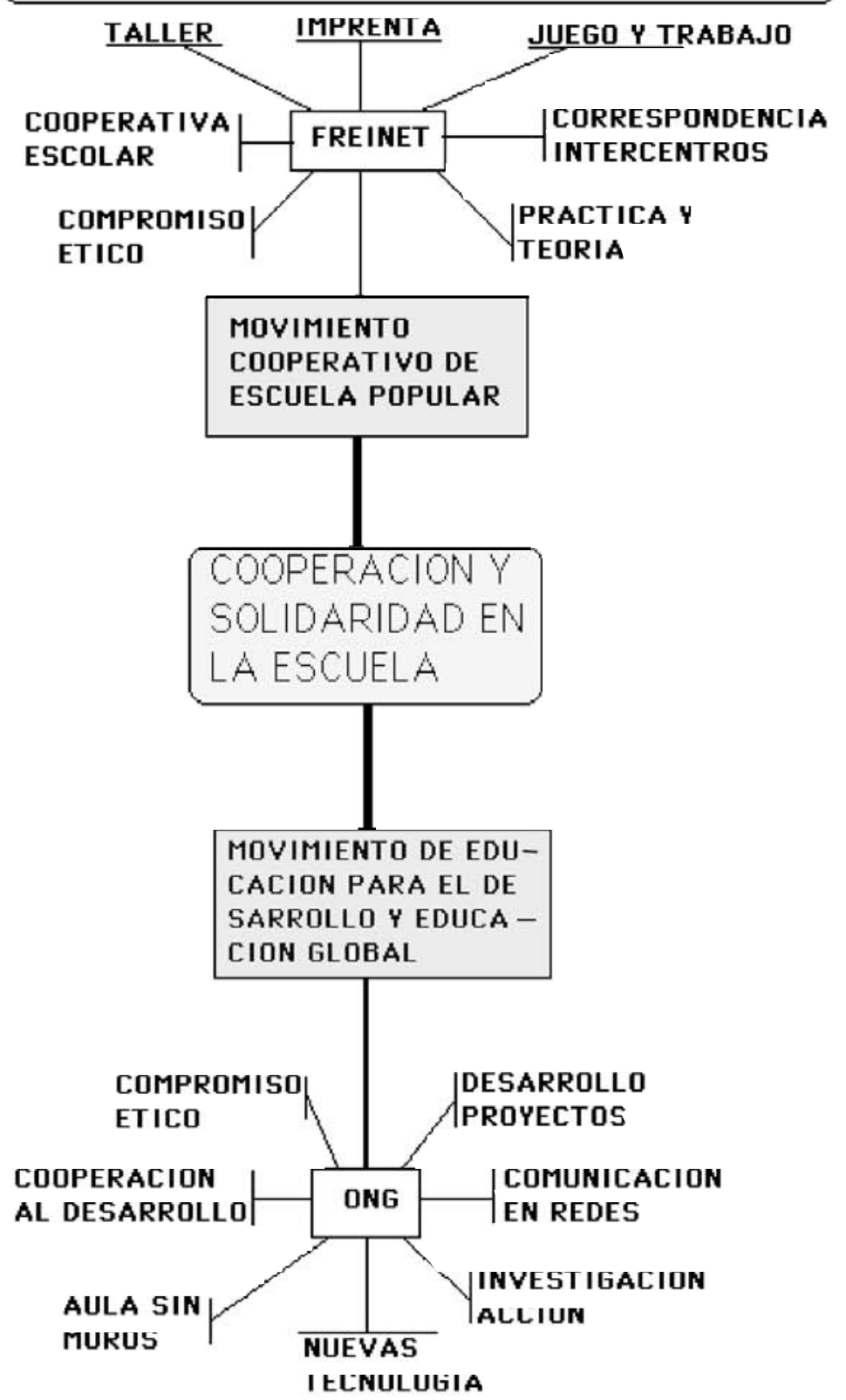

EDUCACION CRITICA PARA LA POSTMODERNIDAD GLOBAL 
Si bien el análisis y debate sobre este fenómeno podemos decir que está en sus comienzos y muy lejos todavía de generar una mínima unidad de criterios incluso en su conceptualización, sin embargo ha sido uno de los términos que más rápidamente han salido de los circuitos académicos para convertirse en un concepto utilizado en el debate social (cuando se escribe el artículo resuenan todavía los ecos de los y las manifestantes en Washington contra la política de globalización del FMI y Banco Mundial).

Otros dos términos se han cruzado rápidamente en este debate, "neoliberalismo" y "pensamiento único". También -y en paralelo- el debate de la globalización ha colocado al tiempo la cuestión de la "relocalización", esto es, la reorganización de los sistemas locales producidas por las prácticas globalizadoras, hasta el punto de que se ha acuñado un nuevo término para reflejar esta doble tendencia de globalización/relocalización, la "glocalización" como rasgo dominante de las dinámicas socioculturales de nuestra época. Y a su vez, el abismo entre el conjunto de las dinámicas y problemáticas agudizadas por estas tendencias y la débil capacidad de reacción de las sociedades frente a aquellas, ha servido para caracterizar a la sociedades de nuestra época como "Sociedades de Riesgo".

No es posible en este artículo pretender esbozar siquiera mínimamente los rasgos teóricos y analíticos que acompañan a este complejo debate y a las conceptualizaciones que les acompañan, sin embargo, sí se hace necesario situar algunos elementos relevantes para el análisis que pretendemos esbozar aquí.

\section{1.a) Sobre la "Naturalización" del orden global}

Es necesario poner en evidencia el carácter interesado e ideológico de las posiciones que pretenden presentar estas tendencias del desarrollo económico y social como "naturales" e "inevitables". Esto es, pretenden velar su carácter de estrategias y orientaciones construidas desde determinadas élites y poderes hegemónicos como únicas alternativas a las diversas facetas de los conflictos explícitos y/o latentes existentes en nuestra época. Este tipo de aproximaciones pretenden hurtar el debate a las comunidades sociales sobre las diversas medidas que van aparejadas como "inevitables". Se intenta así crear un consenso en las llamadas opiniones públicas y mayorías sociales en torno a todo un conjunto de cuestiones estratégicas que deben ser aceptadas como tales y eliminadas del debate democrático.

a.1) Entre estas cuestiones está la "naturalización" de la reordenación económica global con sus cohortes de aumento de pobreza, destrucción de tejidos industriales y la "irremediabilidad" del paro y empobrecimiento añadido. Estos aspectos se presentan como coyunturas negativas necesarias para una posterior expansión futura que suponga un nuevo equilibrio frente a las brutales desigualdades, pérdida de derechos y marginaciones que acarrean en el presente ${ }^{1}$.

1. Resulta brutalmente esclarecedor el Informe de Desarrollo Humano 1999 del PNUD cuando explicita la evolución histórica de la diferencia de ingreso entre el quinto de la población mundial que vive en los países más ricos y el quinto que vive en los países más pobres. Esta diferencia "era de 74 a 1 en 1997, superior a la relación de 60 a 1 de 1990 y a la de 30 a 1 de 1960 . También en el siglo XIX la desigualdad aumentó rápidamente en los últimos tres decenios en una era de rápida integración 
a.2) El intento de consenso en la "inevitable" aceptación de la erosión de las políticas y entramados públicos del Estado del Bienestar ante la necesidad de atraer capítales industriales y financieros que huirían ante cualquier sistema sociopolítico que se empeñe en exigir un mímimo control, regulación y/o exenciones a la rápida acumulación de beneficios, para mantener o impulsar políticas sociales. Se trata de convertir en enemigo de la población todo intento de construir algún tipo de barrera que evite la fuga de recursos y beneficios a las grandes megacorporaciones industriales, comerciales o financieras. Por el contrario debería aceptarse como beneficioso para la población el que esos entramados sociales de bienestar, se reconviertan y reinstitucionalicen para ser explotados y gestionados por la iniciativa privada. Esta, lógicamente y en función de la mejora de su calidad, deberán funcionar con claves de libre mercado, esto es, la libertad de que los pague "libremente" quien pueda "libremente" costearlos.

a.3) Otro rasgo de las consecuencias de esta "inevitabilidad" es el intento de construir como enemigo social a toda opción, discusión o estrategia sociopolítica que pretenda impugnar al sistema de fuerzas que configuran las alternancias y hegemonías dominantes de los estados "democráticos realmente existentes". Así como a los consensos de debate sociopolíticamente posibles que crean estas hegemonías alternantes. En una primera demonización todo lo que se oponga a la aceptación de "lo inevitable-no discutible" será presentado como irreal, absurdo y fuera del debate real. Si además es resistente exitósamente a los intentos de reducción de su influencia social, pasará a ser presentado en una segunda demonización, como alterador del progreso y mejora de la población. Y, si sigue manteniendo su influencia social, pasará a convertirse en enemigo de la "nación" y de su estable, deseable e inevitable sistema "democrático".

a.4) Por último reseñaremos como relevante en esta "naturalización" de entre los múltiples fenómenos que encubre, el velamiento de los riesgos que implica el mantenimiento del actual proceso de globalización y neoliberalismo añadido. Aquí se trata de construir un consenso sociocultural según el cual las sociedades no deberíamos caer en la "sensiblería" y "alarmismo" ante todo un conjunto de botones de peligro que se vienen encendiendo cotidianamente ${ }^{2}$.

mundial: la diferencia de ingreso entre los países superiores e inferiores aumento de tres a uno en 1820 a siete a uno de 1870 y once a uno de 1913. PNUD. Informe de Desarrillo Humano 1999. Madrid, Mundi-Prensa, 1999, pp. 3.

2. Así leo en las páginas de sociedad de la Edición de El País del Martes 18 de Abril "La ONU alerta del "devastador" deterioro de los ecosistemas. ISABEL PIQUER, Nueva York.

El actual deterioro del ecosistema mundial, debido a la constante explotación de los recursos naturales, podría tener consecuencias devastadoras sobre el desarrollo humano y la vida del resto de las especies animales, asegura el informe de la ONU World Ressources 2000-2001, hecho público ayer. El estudio recomienda a los gobiernos que revisen sus políticas medioambientales y estudien nuevas formas de crecimiento económico si quieren conservar los recursos más esenciales para el hombre.

Las conclusiones del informe elaborado conjuntamente por la agencias de desarrollo y medioambiente de Naciones Unidas, el Banco Mundial, y el Instituto de Recursos Mundiales, son escalofriantes: la mitad de las tierras fértiles han desaparecido en los últimos cien años; los bosques mundiales también ha perdido la mitad de su superficie debido a las crecientes necesidades de alojamiento de la población mundial; el 9\% de las variedades de las especies de árboles corren riesgo de extinción; la deforestación tropical excede los 130.00 kilómetros cuadrados por año; las flotas pesqueras son un $40 \%$ más grandes de lo que los oceanos pueden soportar; el $20 \%$ de los peces de agua dulce están en 
La lista de señales de peligro podría ser interminable ${ }^{3}$ en el terreno ambiental, en el de la brecha norte/sur, en el de aumento y generalización de las bolsas de pobreza y marginación, en el de extensión de conflictos zonales, en la proliferación de conflictos racistas, en el ascenso de las nuevas derechas protofascistas, en la persistente vulneración de derechos de personas, comunidades y culturas, en la pérdida de autoridad y de capacidad regulativa y negociadora de las instancias internacionales más representativas, en el de control social de las nuevas investigaciones científico-tecnológicas, en el del control de las comercializaciones alimentarias, en el de proliferación de enfermedades no controladas, en el de la extensión de comercios y mafias ilegales pero muy lucrativas,...

Según la versión dominante en cambio, todas estas señales de alarma deberán ser obviadas por las mayorías sociales pues el propio sistema se encargará en su desarroIlo normal de irlas corrigiendo y aminorando. Las mayorías sociales deberán dejar fuera de su debate democrático estas cuestiones y dedicarse a producir, divertirse y consumir -según las posibilidades de cada estrato social- confiando en que las diversas élites de especialistas y expertos acertarán en el antídoto necesario para cada una de ellas. Quien pretenda crear debate y alarma en torno a ellas deberá ser relegado como anticientífico, alarmista, antisocial y probable sujeto/objeto de un necesario control social especializado.

\section{1.b) Sobre las visiones y análisis de la globalización}

Se hace necesario comprender, profundizar y debatir el carácter y lógica de la glocalización, sometiendo a revisión los diversos análisis que pretenden presentarla como derivada de una única lógica, la de globalización económica, obviando así las condiciones y fuerzas bajo las que se produce las dinámicas de transnacionalización política, social, cultural, comunicativa, etc... Bien se opte por profundizar en análisis derivados de la lógica del desarrollo del sistema mundial capitalista, en lectura de Wallerstein, bien en otros análisis que pretenden buscar claves de globalización en esferas parciales, reorganización global de los sistemas de poderes, de las producciones culturales, de las agencias sociales, de los sistemas de acumulación,... parece inevitable profundizar en las interacciones entre estas diversas lógicas forzosamente contradictorias y en sus impactos sinérgicos en los diversos ámbitos y sistemas locales... ${ }^{4}$.

peligro de extinción. Estos sólo son algunos de los datos que avanza el estudio que pone de relieve la absoluta despreocupación por el medio ambiente de los países ricos y pobres." Sin embargo la página de portada del mismo dia suspira aliviada porque "Las bolsas europeas superan con leves caídas el temido 'lunes negro' "

3. Así se habla y se intenta teorizar sobre las llamadas "sociedades de riesgo". J. Rodriguez Martinez (1999) lo expresa como "La sociología del riesgo, en términos generales, se ocupa de la amenaza que el propio sistema tecnoindustrial en su fase de globalización representa para el medio en que vive, esto es, para el medio ambiente y para el medio social... aparición de efectos y conflictos no previstos e, incluso, no pretendidos por la sociedad industrial... La sociedad de riesgo en que culmina la modernización de la modernidad se instala en un presente amenazado, ante un futuro contingente y de espaldas a un pasado que ni niega ni reclama porque no lo puede culpar ni añorar eternamente".

4. Para este debate resulta muy interesante Ulrich Beck ¿Qué es la globalización? Falacias del Globalismo, respuestas a la globalización y el volumen bajo la edición de R. Ramos Torre y F. García Selgas Globalización, Riesgo y Reflexividad. Tres temas de la teoría social contemporánea. 


\section{1.c) Sobre la importancia de las resistencias}

Se hace igualmente inevitable para toda perspectiva crítica y alternativa, apreciar las dinámicas e impactos de la glocalización no sólo desde el punto de vista de las tendencias dominantes, sino también desde las dinámicas de resistencia social, también glocales, que originan. Estas reintroducen conflictos y brechas en las dinámicas dominantes obligando a reacomodaciones y renegociaciones de los procesos y tendencias. Si algo merece ser revisado son las lógicas que pretende presentar los nuevos procesos y tendencias como productores de un tipo de dinámicas consistentes y coherentes siempre con los sistemas sociales hegemónicos de orden.

En estas perspectivas de orden se hacen sólo visibles las lógicas más funcionales para los sistemas de poderes. Cuando en realidad, las tendencias realmente existentes, son las resultantes de diversas reacomodaciones surgidas en conflictos y choques entre intereses dominantes y contrahegemónicos, que los nuevos fenómenos también desencadenan y ponen en marcha, a veces dificultando, a veces obligando a negociaciones, a veces abriendo direcciones insospechadas. No siempre estas contratendencias responden a lógicas sociales alternativas, muchas veces responden a las propias incoherencias y limitaciones por intereses contradictorios entre los diversos estratos y sectores de poder, provocando resistencias y extrañas alianzas con la lógica dominante,...

Pese a ello, y en consecuencia, estas dinámicas refractarias a la dirección dominante en los diversos campos de las tendencias glocalizadoras existen realmente y reflejan sus dificultades. Pero, además, y de forma especial, hacen visible el carácter no natural, ni inevitable, de lo que acaba siendo impuesto y construido socialmente.

\section{1.d) Producción y socialización cultural de las hegemonías}

Lo ya expresado adquiere cierta significatividad al aceptar una de las contradicciones-base en la actual situación del desarrollo social. Por un lado, la extensión del formato de democracia representativa en las sociedades locales. En este, la ciudadanía -aunque sólo de vez en cuando- es llamada a expresar su opinión existe un ámbito de ciertas libertades que permite la organización y acción de agencias mediadoras, lo que parecería expresar una cierta capacidad de control y debate de las decisiones sociales. Por otro lado contradictoriamente se da un proceso de concentración , transnacionalización y opacidad mayor de estratos de poderes con capacidad de decisión e imposición real de tendencias coyunturales y estratégicas en beneficio propio sin ningún control democrático real.

Esta contradicción entre una aparente extensión de la transparencia y control de las mayorías sociales y una concentración y velamiento real de las agencias con poder real, sólo es mantenible a condición de una poderosa y persistente gestión cultural y producción de opinión social que desvíe, oculte y la haga sostenible y no conflictiva. Es necesario construir y producir, social y masivamente como deseable, aquello que las tendencias dominantes de los poderes realmente actuantes consideren conveniente. Esto no está exento de serias contradicciones y desajustes no siempre previsibles, por lo que necesita una considerable acción estratégica que permita producir y comunicar culturalmente, socializar y resocializar, articular social e institucionalmente, lo 
deseable para la mayoría, coexistiendo con el control y anormalización de lo indeseable, de lo "desviado y minoritario".

En este proceso tres grandes pilares se convierten en estratégicos, las agencias de producción y comunicación cultural y de opinión pública, las instituciones educativas y las instituciones de organización controlada de la opinión pública, bien generales o específicas.

- El primer pilar orientado a la configuración de las visiones normalizadas que deben aparecer como producto del consenso de una mayoría plural pero cuyos límites de disenso deben ser delimitados como aceptables. Es necesario construir un entramado cultural donde sea posible que la diversidad y pluralidad puedan percibirse como propios de una sociedad abierta e individualizada, al tiempo que se masifica y asegura férreamente el control central de lo que no puede ser movido, discutido. Se trata bien por aceptación positiva de lo "realmente existente $^{\prime \prime}$, o por impotencia ante lo alternativo no existente, que toda posibilidad "utópica", esto es, todavía sin lugar, ni siquiera sea posible ser pensada.

- El segundo pilar, sobre el que profundizaremos, orientado a asegurar sistemáticamente los límites de autoconstrucción de la pluralidad y normalidad aceptable en la inserción social de las nuevas generaciones.

- El tercer pilar orientado a asegurar la representación del disenso para su negociación y acomodación regular en los límites de lo posible y aceptable por los poderes hegemónicos. Y ello porque el conflicto debe ser regulado y controlado. Dada la inevitabitabilidad de conflictos y desigualdades, se necesita un cierto nivel de negociación en el reparto de riqueza, poder y prestigio, con algunas mayorías de ámbitos locales privilegiados. Este nivel de negociación es complejo y cambiante en el tiempo y el espacio, está en función de una geostrategia transnacional definida por la importancia de los sujetos implicados, de lo que representan y, lo que signifique el acuerdo, en el orden mundial.

Sin embargo todo ello comporta un cierto nivel de equilibrio inestable que es fuente de conflictos y reequilibraciones de diversa intensidad, ubicación y duración. Así, por ejemplo, los medios de comunicación deben jugar en el ámbito del consenso y la producción de opinión pública controlada, pero también están en competencia por el control de audiencia; entre las instituciones que articulan/negocian el disenso/consenso están por ejemplo los Sindicatos, que participan en el consenso institucional pero debe también responder a sus afiliados y votantes; y a su vez, audiencias, afiliados y votantes dependen en parte de la negociación más amplia del reparto/distribución de riqueza, status, etc... lo que también es un orden en transformación dinámica y conflictiva.

En definitiva si algo es posible apuntar de este conjunto de elementos, es la situación de riesgo y complejidad -Geopolítica del Caos para algunos- que definen la actual situación. Siguiendo a Ignacio Ramonet "Asistimos a un espectáculo insólito: el de un ascenso de la potencia de las empresas planetarias frente al que los contrapoderes tradicionales (sindicatos, partidos, prensa libre) parecen cada vez más impotentes. Por primera vez, el fenómeno principal de nuestra época, la globalización, no está siendo pilotado por los Estados que, frente a las empresas gigantes, pierden progresivamente sus prerrogativas: ¿Pueden los ciudadanos dejar que todo esto siga su curso? 
¿Cómo oponerse a las convulsiones planetarias de nuevo tipo que amenazan la democracia?", añadimos como pregunta específica ¿qué puede hacerse desde la educación formal ante todo esto?

\subsection{El impacto educativo}

¿Cual es el papel asignado a la Educación en esta fase de Glocalización? ¿Cómo está siendo reordenada y configurada por ésta?. La respuesta está lejos de ser clara ni tampoco unificada. También aquí se nos hace imposible esbozar un análisis con una mínima consistencia revisando las diversas lecturas que se pueden estar sugiriendo, intentaremos centrarnos sólo en algunas cuestiones que puedan ser relevantes para el análisis.

\section{2.a) Modernidad y educación}

Si presentamos de forma un tanto esquemática el papel histórico asignado a los sistemas educativos en la plataforma de la Modernidad podemos vislumbrar un conjunto de cometidos que se suelen denominar como funciones sociales de la educación. Desde ahí podemos reflexionar en mejores condiciones sobre las nuevas reacomodaciones en la época de la Globalización.

La Modernidad pretendió construir un nuevo consenso con nuevas racionalidades para la construcciòn y mantenimiento del nuevo orden social. Entre estas:

- una racionalidad productiva/distributiva para una creación expansiva de bienes que permitiera pasar de un orden de carestía a un orden de la abundancia con una supuesta lógica de que su expansión y desarrollo iría haciendo sociedades más ricas y equilibradas,

- una racionalidad en torno al poder identicada con el Estado "nacional" donde su capacidad de soberanía absoluta permitiera ordenar y equilibrar los desajustes sociales que el propio sistema económico pudiera introducir en su ambito definido,

- una racionalidad en torno a la hegemonía de un sistema cultural donde la institucionalización de la ciencia y la técnica permitiera el conocimiento y control de la naturaleza y el ordenamiento social para un uso integrado y productivo,

- una racionalidad socializadora según la cual los sistemas educativos deberían asegurar la ubicación de las nuevas generaciones como agentes de los nuevos sistemas productivos, ciudadanos en torno al nuevo sistema social y estatal, y receptores de la nueva cosmovisión, cultura y conocimientos. En definitiva, deberían servir para desarraigar las bases del viejo régimen en las comunidades sociales rurales y/o urbanas para insertarlas en el nuevo complejo de la sociedades capitalistas.

Naturalmente una mínima reflexión crítica del devenir histórico de la Modernidad muestra la construcción e imposición conflictiva y violenta de todo este sistema de consensos, pero lo que nos interesa resaltar es como en la actualidad la globalización ha agudizado la subversión de estos cuatro pilares. En efecto, el desarrollo de la moderni- 
dad ha agudizado hasta límites insospechados viejos problemas en una dirección contraria y ambigua respecto a las finalidades de implícitas en aquella racionalidad.

- Ha aumentado la desigualdad como condición del crecimiento económico, la construcción exponencial de necesidades en consumidores con recursos como condición de reproducción del circuito acumulativo/productivo, la generaci;on de desechos materiales con alteración de ecosistemas, la marginación de humanos "desechables" innecesarios ni para la producción ni el consumo...

- Ha minorado la capacidad reguladora y equilibradora de Estados cuya soberanía es cada vez más difusa y con pérdida de su centralidad en la capacidad de ordenar y racionalizar las dinámicas de todo orden que trascienden sus límites...

- Ha solidificado unos complejos científico/tecnológicos que transcurren entre sus inercias corporativas y la supeditación a la agenda de poderes que escapan a su control... Incapaces de presentar visiones coherentes y empujados a una crisis persistente entre su misión de ofrecer respuestas a las comunidades sociales y los formatos parcializados, burocratizados e interesados desde los que producen e investigan.

- Ha burocratizado unos sistemas educativos que pierden su centralidad en el control de la socialización cultural, política y productiva, desbordados por dinámicas y contextos con mayor capacidad de influencia y regulación.

\section{2.b) Crisis y retos educativos ante la globalización}

Según lo anterior los sistemas educativos se encontrarían en un proceso crítico derivado de las transformaciones que la globalización ha introducido en el ámbito económico/social, socio-político y cultural. No sólo en cuanto a su capacidad de ejercer su función específica sino en su papel de servir de puente mediador con los otros arriba sugeridos tres pilares de la Modernidad, es decir en su capacidad de reproducción social.

A tenor de todo lo que llevamos dicho glocalización debe estar alterando la situación de los sistemas educativos al menos en los siguientes aspectos:

- En cuanto a sus bases materiales y organizativas, esto es la capacidad de los Sistemas Educativos para cumplir su función de instrumentos organizados e institucionalizados de socialización e integración en los diversos ámbitos de la reproducción social

- En cuanto a la selección, construcción y organización del curriculum, la crísis de determinación de relevancia ética y social del qué, cómo y para qué

- En cuanto a las formas de trabajo, comunicación en interacción; instrumentos y recursos, organización temporal-espacial, relación con el mundo exterior

- En cuanto al sistema de investigación y evaluación de su funcionamiento real y deseable, asì como en la determinación de las pautas y estrategias de renovación/transformación

Todo ello parece que debe estar siendo erosionado y reconfigurado por las siguientes tendencias. 
- Por las nuevas prioridades asignadas a la relación educación sistema productivo tanto en sus vertientes locales como globales.

- Por las nuevas estratificaciones sociales con un aumento de la diversidad de contextos e intereses que los diversos sectores y grupos sociales demandarían como necesitados de respuesta educativa.

- Por las transformaciones del orden político estatal cuya capacidad de regulación y control del conjunto del sistema se ve sometido a tensiones. En la capacidad de asignación de recursos para políticas educativas públicas de calidad y por la competencia con los espacios de privatización educativa.

- Por las nuevas formas de socialización cultural que determina y expande el orden de la glocalización en contradicción con los valores y formas organizativas y culturales clásicas de las instituciones educativas.

- Por la exploxión caótica de los paradigmas y contenidos científicos-tecnológicos relevantes que convierten en imposible un reduccionismo de "conocimiento básico indispensable" para alfabetizar a la ciudadanía en una comprensión significativa de su presente y futuro.

- Por las nuevos formatos tecnológicos que están implicando mutaciones culturales de aprendizaje, comprensión, construcción expresiva, comunicación e interacción social y que afecta a los contextos y formas de la relación de enseñanza/aprendizaje.

Por tanto toda alternativa que desee construir estrategias como la que pretendemos de educación para la solidaridad y cooperación debe construir discursos y estrategias para afrontar como mínimo aspectos como los siguientes:

a) El impacto derivado en la dinámica de expansión/regresión del sistema educativo en el seno de las sociedades locales. Lo que implicará a su vez varios aspectos. Por un lado las políticas de orientación, sostenimiento, expansión, cualificación y dotación de recursos de los sistemas educativos públicos para afrontar los retos del aumento de desigualdad, multiculturalidad, impacto de las nuevas tecnologías, nuevas condiciones de aprendizaje, competencia transestatal, nuevas condiciones de la estructura productiva, nuevos contextos de la producción y comunicación cultural,....

b) El impacto derivado de las políticas neoliberales en la relación entre sistemas públicos / privados de la educación. Dentro de las políticas erosivas del estado del bienestar la minoración del espacio público orientado al conjunto de la población versus un espacio privado orientado con claves de competencia de mercado, o intereses ideológicos específicos. Este tipo de impacto afecta a todas las esferas de la configuración y acción escolar por cuanto tiende a configurar un nivel de eficiencia y configuración de criterios de calidad en la competición por la atracción de determinados sectores sociales al tiempo que ubica otros sectores en espacios escolares de mayor fragilidad.

c) El impacto derivado de la configuración de un orden del dia en la Agenda de preferencias y criterios de selección cultural del curriculum en las instancias administrativas. Tanto la selección y organización del curriculum, como el horizonte de investigación y debate educativo, el formato de reforma e innovación 
curricular, el perfil de formación y adecuación del profesorado, los criterios de idoneidades metodológicas, la panoplia de recursos y el formato de su utilización, los criterios de evaluación y revisión curricular,... son sometidos a las tendencias y poderes dominantes en su análisis y decisión sobre los cambios funcionales necesarios en la relación escuela-sociedad.

d) El impacto derivado de la configuración de un perfil de docente y acción educativa competente que tiende a imponerse sobre el conjunto de crisis vividas por el profesorado. Los discursos generan un horizonte teórico y práctico que pretende convertirse en la clave de autopercepción profesional, individual y colectiva, relectura del momento educativo y sus agentes, ordenación de la práctica, sentidos de la evaluación,... Naturalmente esto no quiere decir que estas lecturas no tropiecen con serias dificultades y contradicciones en su intento de hegemoneización de la cultura docente, desde luego, el espacio de resistencias y configuraciones alternativas existen dadas sus limitaciones en la explicación y comprensividad de la dinámica escolar pero son sin duda muy significativas.

e) El impacto derivado de la irrupción de todo un entramado de nuevas tecnologías en la escena social y que producen un impacto independientemente de su grado de inserción en los sistemas educativos. Tecnologías de la Información y Comunicación que llegan a los agentes educativos reconfigurando sus formas de acción y pensamiento a una mayor velocidad de lo que la escuela tradicional llega a asumirlos y reinsertarlos.

f) El impacto derivado de una consideración de las diversidades culturales y personales que presenta un alumnado socializado en nuevas prácticas sociales ante las que reaccionan individual y colectivamente construyendo sensibilidades, perspectivas e intereses genuinos. En definitiva, claves de una cultura postmoderna con pautas, recursos, redes, instrumentos y rituales de socialización de las nuevas generaciones que aumentan la diversidad de sentidos, intereses y valores de las comunidades y "subculturas" estudiantiles que chocan contra los muros de las viejas instituciones educativas y con las que habrá que pactar críticamente.

\section{2.c) Predisposiciones y visiones del profesorado}

La erosión de estas nuevas condiciones es cada vez más visible a nivel social y educativo lo que provoca sucesivos intentos de Reforma Institucional controlada. Pero, sobre todo, es especialmente sentido dia a dia por los y las docentes que experimentan cada dia como la socialización de la Cultura con mayúsculas que tratan de acercar a sus estudiantes encuentra el rechazo más o menos abierto cuando no la indiferencia. Si bien la diversidad del profesorado también aumenta, cabe situar al menos cuatro formas básicas, de reacción.

a) La de aquellos y aquellas que entienden que se trata de un problema de la falta de motivación, capacidades o intereses de las nuevas generaciones ante las que no se puede hacer nada salvo "aguantar el chaparrón" aferrándose más a las viejas prácticas y los valores "científico-culturales", exigiendo una acentuación, eso sí, de orden y control. Reforzando con ello una lectura conservadora y autoritaria de la crisis y refugiándose en la atención a las minorías que conectan con su 
percepción de la relación enseñanza / aprendizaje. En general adoptan una posición desconfiada ante proyectos de Reforma e Innovación Educativa dado que entienden que sirve para aumentar el desorden y el caos. Este sector se diferencia de los tres siguientes en que renuncia a todo intento de cambio por entender que su práctica profesional y sus saberes no deben ser reformulados.

b) La de aquellos y aquellas que centran el análisis en una perspectiva fundamentalmente "técnica" y tratan de buscar las razones de la crísis en alguna parte del artefacto teórico metodológico de la excelencia pedagógica buscando nuevos formatos, estrategias y técnicas, recursos, que permitan obtener mejores resultados de aprendizaje/enseñanza. Desde su punto de vista, la crisis puede y debe ser comprendida y resuelta en el campo meramente pedagógico e interno del sistema educativo. En general son conscientes de que las prácticas usuales escolares resultan cada vez más anticuadas ante los nuevos contextos que viven los y las estudiantes, pero se trata de re-encantarles, re-motivarles, cambiar las formas y el ropaje de la Vieja Cultura, también con mayúsculas, dado que en el fondo es un problema de crisis de la transmisión.

c) La tercera perspectiva agruparía a lo que Grundy, entre otros denomina, el campo de los enfoques "prácticos" o "comprensivos". Esto es el de aquellos y aquellas que sitúan el discurso en un análisis de crísis de comunicación e interacción de las diversas culturas que se dan cita en el quehacer educativo. Entienden que el currículum es una selección cultural que implica un universo de contenidos, valores, formas de relación y comunicación, criterios de evaluación, formas de participación,... que sin negociación y participación educativa en diversos campos de la acción educativa, producen un conflicto y marginación y subordinación de las culturas estudiantiles con menor sintonía con el currículum y cultura escolar. Están interesad@s por tanto en una innovación básicamente comunicativa y de interacción y negociación donde se trata de reconstruir formas nuevas de acceso al conocimiento incluso sometiendo a críticas y revisiones más o menos radicales los valores, contenidos, formatos y prácticas del curriculum tradicional.

d) La cuarta y última perspectiva podría situarse en el campo de las perspectivas críticas, cuyo centro y punto de referencia colectivo -lo que no quiere decir demasiado unificado- radicaría en una lectura de la crísis más allá de los muros escolares intentando poner en relación, hacer comprensible la crisis escolar en íntima relación con la crisis y dinámica social. Estos sectores se plantean una reflexión crítica sobre el currículum, más allá de las formas comunicativas y/o técnicas de las visiones desde el interior de las aulas y tratan de reflexionar sobre los mecanismos de relación entre los formatos culturales y estratificados de las prácticas y recursos del sistema educativo y los formatos, estratificaciones y diferenciación de poderes en la dinámica mundial. Están interesados por aspectos cómo las claves diferenciales de género, etnia y clase, bajo las que se construyen la cultura escolar y sus relaciones con las resistencias y construcción de prácticas y dinámicas alternativas en la vida escolar y comunitaria. Su orientación pretende engarzar las innovaciones escolares con los espacios de innovación y transformación social. 
Estos cuatro tipo de perfiles, pueden servir de base para definir una toma de posición ante la crisis de los sistemas educativos y de las diversas alternativas sugeridas, especialmente la opción reformadora que en el estado español ha definido en buena medida la agenda educativa del último decenio. Sin embargo no nos dice demasiado sobre la diversa influencia que tienen en la práctica y cómo configuran el discurso docente dominante, incluso a la hora de definir el carácter de la crisis educativa.

Conocer la sociología organizativa del profesorado quizá nos permitiera clarificar algo más el panorama. Dos espacios pudieran ser significativos en una prospección de este tipo, el estado organizativo de los Ilamados Movimientos de Renovación Pedagógica y, el estado de la organización sindical de los y las enseñantes así como el discurso de estas opciones sindicales en torno a la formación y práctica de los y las profesionales de la Educación.

\section{RESPUESTAS COMO SOLIDARIDAD Y COOPERACION}

Un análisis aunque sea somero sobre las respuestas que se están gestando desde compromisos de solidaridad y cooperación requiere revisar dos tipos de aproximaciones, la respuesta institucional, es decir, la respuesta de la actual Reforma Educativa, y, por otro, las respuestas no institucionales que se están fraguando, tanto desde el interior del propio sistema educativo, es decir, el campo de la Innovación y Renovación del propío profesorado y de las agencias externas al propio sistema, esto es, el campo de ONGDs y Plataformas Sociales de la Solidaridad y Cooperación.

\subsection{La Respuesta de la Reforma en Curso}

La actual Reforma Educativa ha introducido en los curricula de las diversas etapas del sistema educativo además de las áreas tradicionales un conjunto de enfoques educativos aglutinados bajo la denominación de ejes, líneas, temas "transversales" ${ }^{5}$. En

5. Si bien el análisis de la conceptualización de la transversalidad en los diversos diseños curriculares desborda el propósito de este artículo, recogemos por su interés la explicitación de la transversalidad tal como aparece en el curriculum de la Eso de la Comunidad Autónoma Vasca (decreto 213/1994, de 21 de Junio por el que se establece el curriculo de la Educación Secundaria Obligatoria para la Comunidad Autónoma del País Vasco (BOPV 155/1994 de 17/08/94). Así, el texto, plantea como consideración que la organización del currículum en áreas no debe entenderse como opuesto a dar respuesta a nuevos cambios problemáticas y demandas sociales "cada día más vivas en la sensibilidad colectiva, que parten del reconocimiento de que la comunidad humana está formada por personas cuyas diferencias deberían aportan diversidad y riqueza -y no jerarquía- que desean convivir en un medio ambiente equilibrado, donde puedan vivir saludablemente, desarrollando su capacidad afectiva, regulando sus tiempos de ocio y trabajo e integrándose en un medio social basado en la igualdad de derechos entre las personas, al margen del sexo, la raza, la religión, la condición física y social o el pueblo al que pertenezcan. Un medio social que planifique racionalmente el consumo de los bienes existentes en función de cubrir las necesidades humanas individuales y colectivas, descarte la violencia como instrumento de solución de los conflictos personales y sociales, potencie la convivencia humana basada en la justicia, la tolerancia y solidaridad y abogue por la expresión libre del pensamiento, a través de los diversos medios y fórmulas de comunicación". Esto representa un reto y compromiso educativo que debe ser recogido por los centros para su tratamiento de "forma sistemática, continuada y coherente". 
este sentido la Educación para el Desarrollo ${ }^{6}$ aparece, en unos casos, como una dimensión de la Educación para la Paz, y, en otros (Comunidad Autónoma del País Vasco y Andalucia), como una transversal específica.

Aunque la formulación legal en los diseños curriculares no asegura por sí misma una práctica realmente transversal en los centros educativos $-\mathrm{y}$, desde luego no puede esperarse que funcione como fuente de referencia teórico-ideológica para los y las docentes. En cualquier caso y dado que constituye un elemento de referencia que aunque sea formalmente todos los Centros en sus Proyectos Educativos y Curriculares deben asegurar, conviene apuntar algunos rasgos de las condiciones en que se está vehiculando en la práctica.

\section{1.a) Un status ambiguo para una cultura de la solidaridad}

La inclusión del status de transversalidad es producto de un doble reconocimiento, la insuficiencia de los curricula de áreas para recoger determinadas problemáticas, y, por otro, el reconocimiento de su importancia reforzada por el hecho de que en la práctica grupos de docentes las vienen ya impulsando.

Sin embargo este status resulta especialmente ambiguo. Por un lado se explicita que se trata de enfoques educativos que deben impregnar el conjunto de los curriculos de areas y/o disciplinas -aspecto que se remite a ser resuelto en el segundo nivel de concreción, el proyecto de centro-. Sin embargo, en otros momentos se habla de "temas transversales" cuya acepción es evidentemente más restringida, pudiendo ser entendido como elementos nuevos añadidos a los contenidos de las áreas y/o disciplinas.

Se entiende que las líneas transversales "no amplían de forma significativa los contenidos educativos que se proponen en las diferentes áreas, pero sí implican una forma nueva de ver y abordar de forma relacionada contenidos distribuidos en distintas áreas que adquieren así un peso específico diferente en el conjunto. Esta perspectiva transforma el enfoque pedagógico de las áreas y la organización del currículo, ya que incide en los objetivos, en los contenidos, en la metodología y en la evaluación, evitando que aparezcan estas problemáticas y valores como algo meramente tangencial.. las líneas transversales pueden ser uno de los hilos conductores para dar un enfoque más global a determinados contenidos que se imparten en diferentes áreas, dotando a la acción educativa de una mayor unidad de criterios".

Se señalan cuales son "la educación para los derechos humanos y la paz, para la salud, para el desarrollo, para la igualdad entre los sexos, para el interculturalismo, la educación medioambiental, la educación para el consumo, la educación vial y la educación en los medios de comunicación" Además se entienden que son convergentes y complementarias pues "plantean valores semejantes y pretenden contribuir a un desarrollo integral de las personas de una forma más armónica, completa y equilibrada. No es difícil descubrir las relaciones que se establecen entre nuestro modelo de consumo o de salud y sus interacciones con el medio ambiente; la comprensión más global de las relaciones Interpersonales y la participación grupal a partir de los valores aportados, entre otras, por la coeducación, la Educación para la Paz y para el desarrollo o el interculturalismo...; los instrumentos que para una lectura y un uso crítico de los medios de comunicación nos dan los valores y criterios aportados por las otras líneas transversales... En definitiva, no deben entenderse estas perspectivas por separado, como añadidos de nuevas materias al currículo, sino como perspectivas múltiples que nos permiten una lectura más completa del mismo".

6. Aunque la cuestión de la Educación para el Desarrollo no es la única referencia donde aparece la cuestión de la Solidaridad y Cooperación, sí que puede entenderse como una de las versiones más genuinas donde la solidaridad y cooperación se plantea en su dimensión local y mundial, por lo que entendemos que para el análisis es una referencia clave. 
Pero es que además no encontramos sobre ellas el mismo tratamiento desde un punto de vista legal. Así a veces nos encontramos con decretos específicos diferenciados de los que se proponen como áreas concretas, en otros casos, sólo tenemos referencias indirectas en los propios textos de las áreas. Resulta significativo que la mayor parte del material de desarrollo sobre transversalidad debamos buscarlo fuera del ámbito legal, en los materiales de apoyo y orientación de cada administración. Y resulta Ilamativo que salvo en los decretos específicos sobre Educación en Valores, cuando aparecen referencias legales explícitas -como en el caso de la Educación Ambiental- suela haber haber algún tipo de concierto con la correspondiente administración con competencia (Departamentos con competencia Ambiental).

Para complicar el panorama las transversales suelen aparecer, en algunos casos, ligadas a otro campo de referencia como es la Educación en Valores, cuyo status aparece también difuso si pensamos que aparece en parte como enfoque transversal en parte como contenidos en cada área (específicos y diferenciados de los procedimentales y conceptuales), sin definir claramente su relación con lo explicitado como Educación en Valores y/o Transversalidad. Es necesario tener en cuenta que la LOGSE define como contenidos del curriculum tres tipos de contenidos, los Cognitivos o Conceptuales, los Procedimentales y los Actitudinales o Valorativos.

La debilidad de la presencia de la Educación para el Desarrollo es manifiesta desde el punto de vista formal, al menos, si se compara con otras transversales. Sólamente en el caso citado de Andalucía y del País Vasco, la Educación para el Desarrollo aparece con el rango de línea transversal más allá de su inclusión como una perspectiva propia de la Educación para la Paz. En general, se carece de una reflexión sobre el sentido y significado de la E.D ${ }^{7}$. Con todo, la existencia de propuestas específicas con los que la Administración parece estar comprometida y la inclusión específica de la E.D. como tal, es más interesante que la ausencia total de propuestas educativas que puedan orientar al profesorado en su práctica docente.

El conjunto de elementos que se han venido analizando refleja una tensión en el interior de la Reforma Educativa que se plasma en la contradicción entre la idea de transversalidad y la organización curricular en torno a áreas y disciplinas. Los Diseños Curriculares recogen de forma muy desigual ambas fuentes de información curricular y dejan la resolución del problema de la integración en manos de los Centros Educativos como responsabilidad directa del profesorado para que lo incluya en su Proyecto Educativo de Centro.

\section{1.b) El riesgo de la Marginación Curricular}

Aparentemente la decisión es democrática y respetuosa con el principio de Autonomía de los Centros, pero el hecho de que la propia Administración refuerce la organización del curriculum por áreas y que plantee posteriormente la "integración" de la transversalidad, genera un conflicto real no explicitado como tal. En la práctica,

7. Por ejemplo, en la fundamentación y análisis de la relación con el curriculum -siguiendo el modelo de las Carpetas Rojas del MEC- se buscan aquellos objetivos y contenidos relacionables con las transversales, aunque luego no se analiza qué hacer con ellos y lo que se adjunta es un conjunto de estrategias, técnicas y recursos, usuales en las prácticas de Educación en Valores y para la Paz. 
refuerza la tendencia de docentes y centros a reconstruir la transversalidad como un "añadido", como un nuevo espacio al que hay que "hacer hueco" y que además, no es propio de su quehacer profesional habitual.

Existen evidencias de cómo esto produce una "marginación curricular" de la transversalidad a través de diferentes vías:

a) Buscar la inclusión de cada transversal en el área más próxima: ambiental y consumo en el área de Ciencias Naturales ; paz, desarrollo e interculturalidad en el área de Ciencias Sociales; coeducación como responsabilidad de las docentes; lo moral y valorativo en el espacio de Etica y Filosofía....

b) Crear espacios "muertos" en el curriculum. Esto es, suspender la actividad regular para abordar alguna campaña, días o semanas específicamente dedicadas a alguna problemática transversal. Luego el curriculum continúa regularmente

c) La especialización. Crear un espacio curricular, taller, asignatura, optativa, dedicada a una o algunas transversales concretas.

d) Actividades extraescolares

e) Puesta en marcha durante un tiempo de una unidad didáctica relacionada con una transversal.

Existen además, diversas situacionesque refuerzan este procesode "transversalizar" formalmente sin que el curriculum organizado en claves de área y/o disciplinas se vea alterado. Se pueden citar, por su relevancia, algunas de ellas:

- la formación del profesorado (la inicial, la elaborada a través de la práctica, incluso la generada en contexto de reforma donde lo habitual han sido cursos de formación especializada en los que la transversalidad ha estado ausente).

- el aislamiento de las prácticas educativas respecto del medio, desconectadas de la problemática social que aleja sus orientaciones de una dirección crítica e innovadora

- la forma en que se han presentado a los centros los nuevos curricula y proyectos curriculares, donde se ha puesto en primer plano la necesidad de llegar a consensos rápidos, que tienden a ocultar los conflictos y contradicciones que la puesta en marcha de la transversalidad plantea al sistema educativo

- la estructura espacio-temporal de la vida de la institución escolar organizada en torno a las áreas, con tiempos asignados de manera uniforme, en aulas fijas, con docentes especializados dificulta prácticas y dinámicas interdiscipliares e integradoras

- los recursos y herramientas de enseñanza/aprendizaje, los tradicionales libros de texto que incluyen formalmente la transversalidad pero cuya estructura y organización se adecúa realmente a la organización tradicional del curriculum en áreas

- la postura de la comunidad educativa real, cuya preocupación y compromiso con la cuestión de la transversalidad y de los valores es cuando menos conflictiva y tiende a presionar, muchas veces, en el sentido del curriculum más tradicional

- la carencia de articulación estructural entre los sectores y agentes más interesados y comprometidos con el desarrollo de estos enfoques educativos 
- el compromiso de la Administración no debiera acabar con el apoyo a iniciativas existentes, sino que debiera incluir su impulso y promoción. Esta orientación más interesante, requiere recursos de muy diverso tipo pero, sobre todo, exige un compromiso mayor ante las dificultades que plantea su implementación.

- la débil presencia de esta cuestión en el debate e investigación académica en el campo de las Ciencias de la Educación

- la carencia de evaluación de proyectos e iniciativas que promueven la transversalidad, y de análisis de los efectos "ocultos" de las prácticas dominantes de desarrollo curricular

- la débil y/o nula presencia de esta problemática en las estructuras de apoyo del profesorado (Centros de Profesores, Equipos multiprofesionales, Inspección Educativa,...)

- la cultura social hegemónica que impregna la realidad educativa y social con sistemas de valores, prácticas sociales, relaciones de poder, elementos mediáticos, pautas culturales... que reproducen tendencias y discursos contradictorios con estas perspectivas

Todas estas dificultades y contradicciones impiden los desarrollos transversales, en general, y, de la Educación para el Desarrollo en particular, como enfoques críticos e innovadores, con el grave riesgo que conlleva de ubicarlos en el "curriculum oculto" y/o en conexión con la ideología y valores hegemónicos.

Pero es que además, los discursos dominantes sobre las prácticas sociales tienden a visibilizar y poner en primer plano en el ranking del éxito y la correcta integración social, visiones desde la Competetividad Individualista y la carencia de Cooperación, aspectos que la tradición escolar clásica tienden a potenciar mientras penaliza y desvaloriza el trabajo grupal.

\subsection{Las Respuestas no Institucionales}

Y sin embargo, al tiempo, se hace evidente la crisis del curriculum tradicional incapaz de responder ni a las claves socioculturales de las nuevas generaciones, ni a las demandas estratégicas de formar una ciudadanía con un sistema de valores alternativo al dominante. Esto provoca que centros y grupos de docentes, autónomamente o en conexión con plataformas externas, se encuentren cada vez más interesados en buscar formas más integrales y transformadoras para el desarrollo de una Educación que apueste desde un Compromiso Etico y Valorativo por prácticas de inovación y renovación pedagógica donde la Solidaridad y la Cooperación formen parte de un universo cultural que impregne toda la actividad y construcción individual y colectiva. En esta dirección se evidente que allá donde la apuesta por la transversalidad es más integralmente transformadora, global y consecuente, allá donde los agentes implicados adquieren mayor compromiso, la escuela consigue transformaciones en su interior y las proyecta al medio social ${ }^{8}$. Lógicamente ello implica negociar con el

8. Pensemos en la Igualdad de los Sexos/Coeducación, un terreno en el que más se ha trabajado y en el que se comienzan a apreciar algunos cambios positivos $\mathrm{o}$, al menos, donde se evidencian de forma más explicíta las contradicciones propias de un sistema de relaciones sociales y de pensamiento claramente androcéntricos. 
alumnado desde claves cooperativas y de participación sobre aspectos y problemáticas relevantes para su cultura o las del propio medio social y comunitario, mostrando sus claves locales y globales.

Es necesario por tanto considerar el estado de los agentes, elementos, recursos y dinámicas pueden potenciar o dificultar estos enfoques educativos que situan como centro de referencia la cuestión de la solidaridad y la cooperación.

\section{2.a) Movimientos de Innovación/Renovación Pedagógica}

Desde luego no nos encontramos hoy en el momento más boyantes de los Movimientos de Renovación Pedagógica si los entendemos como se construyeron entre los años 60 y 70 muy ligados a la fase expansiva del movimiento democrático antifranquista que en su vertiente educativa sirvió para ligar el movimiento reivindicativo, la revisión cultural y pedagógica junto a la formación y experimentación de los y las docentes.

Estos MRPs sufrieron diversas crisis y mutaciones que hicieron disminuir su influencia autónoma, aunque siguen existiendo. Por un lado los elementos más reivindicativos fueron tomando forma y ubicación en las diversas expresiones sindicales, por otro el retraso de las Reformas Educativas fueron retrayendo a muchos de sus sectores a las prácticas más próximas al centro y aula. Nuevos fenómenos siguieron contribuyendo a su crisis y reformulación, la aparición de fórmulas y espacios institucionales de formación con mayores recursos junto a políticas de individualización de la formación (formación como puntuación para el curriculum, formación separada de prácticas de innovación, presencia de la formación académica universitaria,.. Pero sobre todo la propia propuesta de la que se presentó como gran Reforma que hizo que muchos de los sectores que estaban en la Renovación apostaran y dedicaran sus energías a racionalizar y extender la propia reforma desde la pretensión de que esta incorporarara y extendiera las orientaciones de los propios MRPs. Todos estos elementos entre otros han conducido a que la Renovación Pedagógica en su versión organizada autónoma tenga menor influencia.

Sin embargo han seguido generándose iniciativas de muy diversa entidad y enfoque, desde experiencias muy locales y ligadas a centros concretos y/o grupos de docentes de áreas específicas a experiencias incluso de ámbito transnacional, relacionados o no con las diversas estructuras y convocatorias de las instituciones de apoyo al profesorado, a proyectos relacionados con la universidad, con proyectos de otras instituciones u organizaciones no gubernamentales, incluso si bien de forma débil en los propios sindicatos se han generado algunas iniciativas.. Es decir la renovación pedagógica sigue existiendo, sólo que mucha más dispersa, desorganizada y con pérdida de voz en el panorama y discurso educativo.

Pero merece resaltarse que dentro de este complejo y desigual panorama de la Innovación y Renovación Educativa la cuestión de la Solidaridad y Cooperación tiene vieja raigambre. Así por ejemplo los MCEP, inspirados en la tradición freinetiana siguen siendo un lugar de referencia e inspiración teórico-práctica.

\section{2.a1) Rescatar a Freinet}

En la presentación de este artículo recogíamos un texto freinetiano. Yus Ramos (1997) reinvidica una relectura del pensamiento de Freinet "en el contexto social en que nos 
hallamos en los albores del siglo XXI" dado que nos encontramos ante un "mundo cada vez más globalizado e interrelacionado, en el que las diferentes etnias tienen cada vez mayor proximidad y van creando nuevos conflictos derivados de la desigualdad social y el desequilibrio ecológico a escala planetaria.. es imprescidible dar una proyección mundialista al pensamiento, aún hoy dia influyente, de Freinet, para sobrepasar el marco local y llevarlo al ámbito global... necesitamos un planteamiento global para esta nueva escuela, que interrelacione todas las dimensiones de los problemas que actualmente aquejan a la humanidad y proporcionen una visión sistémica o compleja de los mismos". Interpretación que este autor considera fundamental en una Educación para el Desarrollo como enfoque actual de la Solidaridad y la Cooperación.

Esta pretensión de reutilizar las todavía innovadoras propuestas freinetianas hace interesante profundizar en sus relaciones y aportaciones para esta época de la postmodernidad y la globalización. Así Yus plantea su redimensión en nuevas escalas y visiones mundialistas (relación local-global), con planteamientos sistémicos y complejos (disciplinariedad-transdisciplinariedad), situando así una nueva mirada a una serie de aportaciones de Freinet muy relevantes para el enfoque que venimos explorando. Cuatro cuestiones son desde nuestro punto de vista son especialmente significativas:

\section{El sentido y compromiso de la acción educativa}

Para Freinet la clave del movimiento de Escuela Moderna frente a Escuela Nueva o Métodos Activos es la respuesta a la necesaria "adaptación a las necesidades de nuestro siglo ${ }^{\prime \prime}$. Es una respuesta que se inscribe en las tradiciones emancipatorias de los trabajadores y el pueblo. Popular, Escuela Pública, Escuela del Pueblo, para responder a las "necesidades imperiosas de una clase que siente la necesidad de formar las generaciones nuevas a imagen de la sociedad que vislumbra, cuya edificación majestuosa ya ha comenzado ${ }^{10 \prime}$. Es decir el proyecto educativo es entendido como un proyecto ético político para responder a una época, a unas necesidades, a unos sectores, a un proyecto de futuro. "Se impone una readaptación de nuestra escuela pública para poner al servicio de los niños de esta mitad del siglo XX una educación que responda a las necesidades individuales, sociales, intelectuales, técnicas y morales de la vida del pueblo en la época de la electricidad, la aviación, el cine, la radio, el periódico, el teléfono, la televisión, en un mundo que esperamos que sea pronto del del socialismo triunfante ${ }^{\prime \prime 11}$.

Readaptar, pero no en el sentido de adecuación a unos nuevos contextos tecnológicos y/o socioeconómicos, sino adaptar fundamentalmente en un sentido integral para un futuro alternativo. La lógica de su acción educativa forma parte del conjunto de su compromiso militante político y sindical. Se trata de enmarcar la emancipación de la miseria cultural y la marginación social a través del accionar pedagógico en coherencia con el desarrollo de las organizaciones y cooperativas populares para la

\footnotetext{
9. Freinet, C., Salengros, R. Modernizar la Escuela, p. 5.

10. Freinet, C. Por una Escuela del Pueblo, p. 18.

11. Freinet, C. Por una Escuela del Pueblo, p. 21.
} 
resistencia y transformación social. Se trata de comprender, aprender actuando socialmente, de la misma manera que la acción y organización social comprometida con una orientación transformadora supone la escuela práctica y la escuela de fuego para el movimiento emancipador adulto. Un conjunto de valores impregnando al sentido de la práctica social y se incorpora también al sentido de la propia práxis educativa.

\section{La cuestión de los recursos tecnológicos}

Freinet es consciente de las nuevas y rápidas mutaciones tecnológicas que están atravesando su mundo y cambiando las condiciones sociales pero sobre todo culturales de la sociedad adulta pero sobre todo de las nuevas generaciones. Hoy sin duda hablaría de la Telefonía Movil, de Internet, de los Nuevos Medios de Comunicación, de los Autómatas y Robots, del Vídeo, de las Tecnologías Laser,... Pero sobre todo del impacto cultural que estas egendran y de sus mutaciones en la forma de comprender y aprehender la realidad.

Freinet no pudo introducir el ordenador en el aula, pero introdujo la imprenta. Por cuanto implicaba dar un sentido de trabajo/creación y utilidad social/expresión a la acción educativa. "La inteligencia manual, artística, científica, no se cultiva por el uso de las ideas únicamente, sino por la creación, el trabajo y la experiencia". Los textos producidos en aquella imprenta, textos libres, "eran leidos en la aldea, apreciados ordinariamente por los padres, pero todavía no era suficiente. Nuestros niños querían y merecían un autitorio más amplio. Para lograrlo inicié la correspondencia interescolar... el texto libre se volvía una página de vida, que se comunicaba con los padres y se transmitía a los corresponsales ${ }^{121}$. Las técnicas, los recursos, lo que transcurre y transforma el mundo social y cultural exteno, debe entrar en la escuela, para ser conocido, experimentado, pero especialmente reacomodado para añadirle un sentido social, útil, educativo, capaz de intercambiar mundos, trabajo, creaciones, sueños y problemas, tal es el sentido donde trabajo, aprendizaje, participación y comunicación, toman un sentido.

\section{La cuestión cooperativa}

"No hay auténtico plan de trabajo si no hay participación, formulada o no, motivada por la vida, aunque sólo sea afectivamente; si los interesados no lo eligen y aceptan... El planning de la fábrica tampoco es un plan de trabajo. El obrero no ha participado en su elaboración... no tiene nada de educativo... no hacemos ejercitar ninguna de sus virtudes características, las que constituyen su potencia y su grandeza: la facultad de pensar por sí mismos y expresar su pensamiento, la capacidad de experimentar y crear, la acción decisiva sobre un mundo que les rodea... Son nuestros planes de trabajo, que constituirán la síntesis de ese orden nuevo que estamos estableciendo y que sustituirá paulatinamente a la autoridad escolástica: la cooperación en el trabajo ${ }^{13 \prime \prime}$

12. Freinet, C. Técnicas Freinet de la Escuela Moderna, pp. 18-19.

13. Freinet, C. Los planes de Trabajo, pp. 10-13. 
Trabajo, participación y organización cooperativa son tres elementos que configuran un sistema de referencias educativas claves, no se trata de "motivar" sino que el alumnado se organice para construir su gestión, dinámica de aprendizaje, investigación, evaluación, lo que implicará pactar, negociar, reflexionar, sobre el curriculum en la práctica. Y cuando Freinet habla de cooperativa "se trata de una verdadera sociedad de niños, capaz de administrar la vida escolar casí integramente" ${ }^{\prime 14}$.

\section{El movimiento de los y las docentes}

Con todo, y pese a que Freinet expresa con cierta rotundidad algunas apreciaciones a las que sin duda hoy introduciríamos matices como "la escuela no está nunca a la vanguardia del progreso social.. la escuela sigue siempre con lamentable retraso a las conquistas sociales ${ }^{\prime 15}$, entiende que la posibilidad de esa Escuela Nueva depende de los avances y retrocesos populares, de los gérmenes y dinámicas de la sociedad futura. Y lejos de dedicarse a observar su evolución se lanza a fabricarla. Toda su obra adquiere sentido y significatividad como expresión de una lucha constante por crear un movimiento de los y las docentes, movimiento que impulse, colabore y coopere, en la definición, extensión y experimentación de esa nueva educación. Pero no sólo como puro movimiento pedagógico sino con conciencia de su sentido histórico y social "Debemos ser todos los educadores del pueblo juntos quienes, mezclados con el pueblo, en su lucha popular, llevemos a la realización la Escuela del Pueblo"16

Estos cuatro aspectos pueden desde nuestro punto de vista considerarse herramientas estratégicas para una Educación para la Solidaridad y la Cooperación, no sólo por cuanto definen toda una estrategia de Acción Pedagógica y Social, sino por cuanto se acomodan a los nuevos agentes y dinámicas sociales de la Solidaridad Crítica ante la Globalización.

- Una Selección Cultural del Currículum comprometida con un Proyecto Alternativo. Pensar el currículum, su contenido, sus formas y ritos, sus procesos de evaluación en clave de contribución al entendimiento del mundo complejo en el que se insertan las nuevas generaciones para dotarse de herramientas y perspectivas eticas para una contribución colectiva transformadora

- Una Forma de afrontar unas condiciones de Acción Pedagógica donde la Utilización de recursos Tecnológicos sea una herramienta de trabajo, de participación, de creación de una Cultura y formas prácticas de intervención como agentes ciudadanos comprometidos con un proyecto común.

- Una Forma de considerar a los educadores como posibles sujetos organizados trabajando colectivamente y en relación con los ámbitos y sectores interesados socialmente en avanzar en transformaciones alternativas.

14. Freinet, C. Por una Escuela del Pueblo, p. 167.

15. Freinet, C. Por una Escuela del Pueblo, p. 29.

16. Freinet, C. Por una Escuela del Pueblo, p. 20. 
Sin embargo hay dos aspectos en los que se hace necesario profundizar:

- en primer lugar sobre las nuevas condiciones culturales que las agencias dominantes de producción cultural, comunicación y socialización paralela a la escuela, expanden en el sistema social y con especial incidencia en las nuevas generaciones menos impregnadas de formas culturales anteriores.

- en segundo término en como se relacionan y ubican con las agencias de cooperación y solidaridad.

\section{2.a2) Más allá de Freinet. Nuevos Contextos Culturales y Recursos, Nuevos} Aliados, Movimientos y Organizaciones de la Solidaridad y Cooperación.

Pérez Gómez (1998) en un texto clave para la reflexión sobre el conflicto cultural en las escuelas, señala las distintas culturas y formatos que confluyen a la realidad escolar. A ello, se debe añadir la consideración de la llamada "cultura del espectáculo" como señala J. Ferrés (2000) "Mientras la tecnología de la imprenta tiende a privilegiar una representación del mundo de carácter conceptual, estático, analítico y reflexivo, la cultura del espectáculo tiende a privilegiar de manera prioritaria uan representación del mundo concreta, dinámica, implicativa, sensitiva y emotiva. Unos cambios sociales tan profundos interpelan seriamente a la cultura oficial, que se siente amenazada y que reacciona a menudo a la defensiva, incrmentando las distancias respecto a la cultura popular. La misma institución escolar se siente confusa y desorientada a la hora de asignar responsabilidades por sus propios fracasos e incapaz de ofrecer a la sociedad respuestas satisfactorias".

Según este actor estamos ante una profunda encrucijada cultural en el conflicto entre una inconosfera dominante en la "cultura popular" y la denominada "cultura oficial", cuyos efectos chocan radicalmente con la cultura académica. Sus efectos (voracidad perceptiva, necesidad de concrección, dificultad de concentración, zapping mental como nueva manera de pensar, cultura mosaico, zapping actitudinal ante la dinámica social, sentido de la inmediatez e impaciencia, búsqueda de emotivividad, hiperestimulación sensorial contra racionalidad, dinámismo vertiginoso contra capacidad de concentración, concrección frente la capacidad simbólica, hipertrofia emotiva contra reflexión..) se convierten más allá de la asunción de rasgos individuales en rasgos colectivos. "El espectáculo impregna hasta tal punto la vida de los ciudadanos que en las sociedades más desarrolladas han acabado por convertirse en espectáculo desde la política... hasta la religión... Se ha pasado pues de culturas con espectáculo a una cultura del espectáculo.... Todo se torna virtual: existe para ser contemplado, para ser consumido. La cultura del espectáculo no comporta tanto que tengamos oportunidad de ver cosas que existen o que suceden cuanto que las cosas existan o sucedan para que se puedan ver". Escenario que para la escuela hoy se convierte en auténtica pesadilla, pero cuya influencia tiende aumentar de las manos de las nuevas tecnologías y medios de comunicación, no sólo por su estructuración, sino por la sinergia generada entre ellos.

Por tanto, no es posible abordar hoy un escenario como el inspirado en la fórmula de Freinet sin al tiempo considerar la cuestión de los nuevos formatos tecnológicos y las profundas mutaciones socioculturales que están emergiendo con gran rapidez. Consideremos a modo de ejemplo el caso de Internet 
Irantzu Larrañaga (1996) ofrece la siguiente expansión del número de Hosts en red

$\begin{array}{lll}\text { Mes } & \text { Año } & \text { No de Hosts } \\ \text { Diciembre } & 1969 & 4 \\ \text { Abril } & 1971 & 23 \\ \text { Junio } & 1974 & 62 \\ \text { Marzo } & 1977 & 111 \\ \text { Agosto } & 1981 & 213 \\ \text { Mayo } & 1982 & 235 \\ \text { Agosto } & 1983 & 562 \\ \text { Octubre } & 1984 & 1024 \\ \text { Octubre } & 1985 & 1961 \\ \text { Febrero } & 1986 & 2308 \\ \text { Noviembre } & 1986 & 5089 \\ \text { Diciembre } & 1987 & 28174 \\ \text { Julio } & 1988 & 33000 \\ \text { Octubre } & 1988 & 56000 \\ \text { Julio } & 1989 & 130000 \\ \text { Octubre } & 1990 & 313000 \\ \text { Julio } & 1991 & 535000 \\ \text { Julio } & 1992 & 992000 \\ \text { Julio } & 1993 & 1486000 \\ \text { Julio } & 1994 & 3864000 \\ \text { Julio } & 1995 & 6642000 \\ \text { Julio } & 1996 & 12881000 \\ \text { Diciembre } & 1996 & 17 \text { a } 20 \text { millones }\end{array}$

Y en el pronóstico que hacía para el año 2000 habla de 187 millones de ordenadores conectados y 1000 millones de personas. Tendencia aproximada que corrobora el Informe sobre Desarrollo Humano 1999 "se estimó que más de 143 millones de personas eran usuarios de Internet a mediados de 1998, y se espera que hacia el año 2001 ese número supere los 700 millones". El mismo informe señala la radical desigualdad existente en el uso de la Red de Redes y adjunta un cuadro especialmente significativo. Los países de la OCDE con el 28,8\% de la población mundial, 1.128.000.000 calculada sobre 6 mil millones de población mundial, tienen 132.540 .000 usuarios, esto es, es usuaria el $11,75 \%$ de su población, mientras que el resto del mundo 4.272 .000 habitantes, el $71,2 \%$ de habitantes mundiales tienen 11.460 .000 usuarios, esto es, el 0,27\% de su población, y todo ello para un cálculo de un $2,4 \%$ de la población mundial usua ria de ordenador, esto es, 144.000 .000 de usuarios. Es decir uno de cada ocho y medio ciudadan@s de la OCDE sería usuari@, mientras que en el resto del mundo sería uno cada 370. Y esto sin entrar en el \% de distribución por nivel de estudio, género, clases, etnias, espacios rurales y urbanos, donde la diferencia de estratificación aumentaría tanto en la OCDE como en el resto del mundo.

Los ordenadores han entrado en las escuelas lenta y desigualmente y cuando lo han hecho ha sido fundamentalmente a través de Aulas de Informática utilizadas fundamentalmente por los y las docentes encargados de estas aulas. Los y las estudiantes las utilizan para familiarizarse con la informática y sus programas $y$, bien en esas aulas de los centros, bien en sus casas (un sector reducido lo tienen), para hacer trabajos e 
indagaciones, que en buen número de casos suele ser recoger datos empaquetados ya de Enciclopedias y/o Recopilaciones temáticas, ya de alguna página Web en la Red (todavía un número de estudiantes más reducido) y proceder a pegarlos, eso sí, con formatos de gran calidad de presentación pero donde puede no haber nada suyo e incluso es probable que no haya sido especialmente leidos.

¿Qué indica desde nuestro punto de vista? La expansión de las nuevas tecnologías adquiere unos ritmos de aceleración temporal, aunque desiguales, trepidantes. Pero ni todas las tecnologías son iguales, ni implican sólo cambios tecnológicos. Es evidente que Internet es una red elitista, del Norte, Urbana, de ciertos sectores privilegiados, con una sociología de género masculino y de clase media, sin embargo, frente a otros medios de información/comunicación, tiene una mayor potencialidad democrática y participativa. Puede ser utilizado por pequeños y minoritarios grupos y organizaciones que trabajando en Red pueden hacer llegar sus mensajes, puntos de vista, debates, informaciones, a nivel mundial, lo que sería impensable por otros medios. Permite una comunicación interactiva horizontal (Correo Electrónico, News, Listas de Distribución, Chats,...), donde desde personas individuales a grupos pueden entrar en contacto, organizarse e incluso movilizarse montando campaña (las movilizaciones contra las Instituciones Internacionales utilizando Internet comenzaron a utilizarse ya en el 50 aniversario de la fundación del FMI y el BM, y en las últimas los propios autores confiesan que la red ha sido fundamental para organizar su movilización). Pero además es, hoy por hoy, una Enciclopedia Universal más democrática e intercultural, por cuanto resulta de lo que personas, actores, organizaciones, grupos, decidan meter en la Red. Es por tanto un añadido posible a la Investigación, el Análisis, la Información Alternativa. Pero su virtualidad depende de las condiciones de uso, culturales, técnicas y sociales, de los intereses y expectativas que suscita, de su relación con la problemática y el conflicto social.

Por tanto su uso educativo -desde perspectivas críticas, de solidaridad y cooperación, de orientación transformadora- es urgente y radicalmente necesario pero demanda cambios: requiere aprendizaje, trabajo, reflexión, capacitación, organización, sentido, saberes,... Es decir, todo aquello que la escuela, la educación, podría, debería facultar a condición de transformar su orientación curricular, sus rituales, su distribución espacio/temporal, sus formas de trabajo interdocentes, sus relaciones con el mundo exterior a sus muros, sus formas de construir la participación de todos sus actores, de orientar su trabajo de innovación, investigación, evaluación, sus formas de relación con otras comunidades educativas,.....

En este empeño el mundo alternativo de la Educación no sólo no está solo sino que desde ámbitos bien diversos diversas agencias, interesadas en la Educación para la Solidaridad y Cooperación, en una Educación Crítica y Alternativa a la Glocalización Dominante, diseñan Recursos, Proyectos Innovadores, Alianzas, Préstamos mutuos de Herramientas, etc...

Sin embargo el mundo de la Educación, el mundo de los y las docentes, el mundo de la Investigación y Renovación Pedagógica, el mundo de la Asesoría y Apoyo a los Centros, el mundo de la propia Comunidad Educativa implicada en el Sistema Formal, tiene todavía una débil comunicación e interacción con ese mundo externo de la Solidaridad, de la Educación para el Desarrollo y otros enfoques definidos como trans- 
versales. Es una interacción emergente, es posible verlo en tímidas redes en Internet $y$, también, en incipientes redes y formas de trabajo y apoyo mutuo en la realidad local, pero todo ello todavía en núcleos muy minoritarios.

No se trata tanto de atribuir responsabilidades en esta debilidad -están a ambos lados de los muros- sino de entender las dificultades existentes. Deberemos entender sus distantes tradiciones, formas de trabajo, orden de prioridades, capacitaciones y recursos dedicados a este encuentro, estilos organizativos, etc... como dificultades a ir superando si somos capaces de analizarlas y, lo que es más importante, atribuir prioridad e importancia a su superación.

La tradición de Renovación e Innovación Educativa, aunque débil, tiene interesantísimos aportes a esta confluencia. Los Sindicatos de Enseñanza, también de forma muy incipiente y tímida empiezan a plantearse una actividad más allá de lo puramente reivindicativo. El Mundo de las ONGDs y otras plataformas Solidarias, van afinando su discurso educativo y desarrollando proyectos de mayor interés, abriéndose a nuevas perspectivas de aproximación a las problemáticas clásicas de otras plataformas: Ecologistas, Pacifistas, de Derechos Humanos, por un Consumo Crítico, desde el movimiento Antiracista e Intercultual, del Movimiento Feminista,.. Tímidamente también el mundo académico parece ir empezando a considerar relevante esta temática... Y todo ello en ámbitos y con relaciones y con redes y formas de encuentro muy diversas y flexibles. Todo ello es una esperanza, pero fundamentalmente es un reto para todos y todas interesad@s en promover cambios educativos y sociales en línea Solidaria y Cooperativa. No podemos acogernos a las seguridades de los Grandes Discursos Críticos y Alternativos de la Modernidad que auguraban un futuro inevitable y definían unas estrategias "científicas".

La postmodernidad ha evidenciado que los Discursos son posibles en la medida que sean reconstruidos, pactados, investigados, ensayados y transformados en, y al tiempo, que se desarrolla la práctica, intereses y pactos, de los actores implicados. También ha aportado la centralidad del conflicto como inherente a cualquier práctica social. Los Viejos Discursos han mostrado sus límites pero los problemas que denunciaban no sólo siguen ahí sino que han aumentado a nivel local y planetario y, además, han adquirido tintes cualitativamente diferentes. El reto sigue estando en quienes pensamos que en las aulas y en la realidad social la "utopía" sigue siendo no sólo necesaria sino urgente. 


\section{Bibliografía}

ALBIÑANA, A. (De.) (1999). Geopolítica del Caos. Madrid, Debate.

BECK, U. (1998). ¿Qué es la Globalización? Falacias del globalismo, respuestas a la Globalización. Barcelona, Paidós.

CONSEJO ESCOLAR DEL ESTADO (1999). Informe sobre el estado y situación del Sistema Educativo. Curso 1997-98. Madrid, MEC.

FEDERACIÓN DE ENSEÑANZA DE CC.OO. (1993). Gabinete de Estudios. Encuesta al profesorado de Primaria y Secundaria de la Enseñanza Pública: Opciones y Actitudes ante sus condiciones de trabajo. Madrid, CIDE.

FERRÉS, J. (2000). Educar en una cultura del espectáculo. Barcelona, Paidós.

FREINET, C. (1979). Los Planes de Trabajo. Barcelona, Laia.

FREINET, C. (1984). Técnicas Freinet de la Escuela Moderna. Madrid, S.XXI.

FREINET, C. Por una Escuela del Pueblo. Barcelona, Laia.

FREINET, C.; Salengros, R. (1981). Modernizar la Escuela. Barcelona, Laia.

GIL, F. (1996). Sociología del Profesorado. Barcelona, Ariel.

LARRAÑAGA, I. (1996). Internet Solidari@ La última revolución. Tafalla, Txalaparta.

PARRILLA, A.; DANIEL, H. (1998). Creación y Desarrollo de Grupos de Apoyo entre profesores. Bilbao, Mensajero.

PÉREZ GÓMEZ, A. I. (1998). La Cultura Escolar en la Sociedad Neoliberal. Madrid, Morata.

PNUD. (1999). Informe sobre Desarrollo Humano 1999. Madrid, Mundi-Prensa.

RAMOS TORRE, R.; GARCÍA SELGAS, F. (Eds) (1999). Globalización, Riesgo, Reflexividad. Tres temas de la Teoría Social Contemporánea. Madrid, CIS.

YUS RAMOS, R. (1997). "Desde la Cooperación en la Escuela a la Cooperación para el Desarrollo. (Una relectura del pensamiento de Freinet en los albores del siglo XXI)" en Vázquez, J. (Coord.) Educación, Desarrollo y Participación Democrática. Madrid, ACSUR-Las Segovias. 